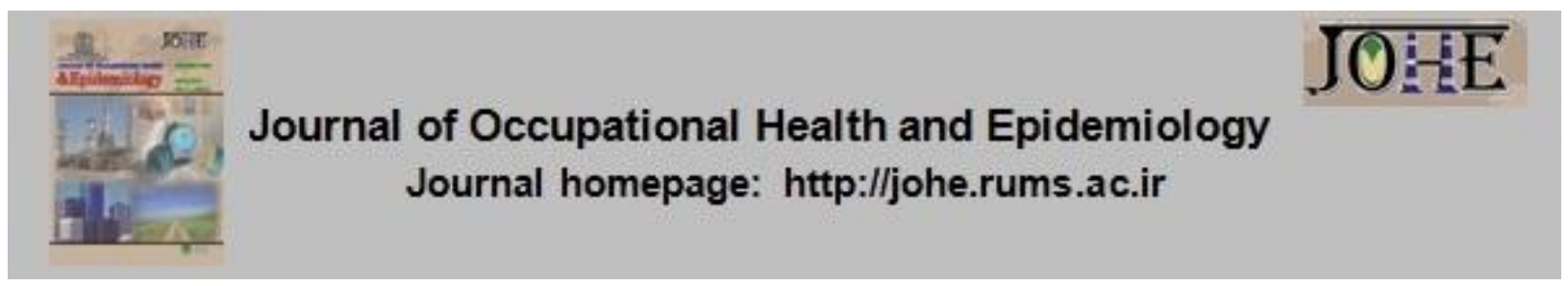

\title{
Epidemiology of incidents and accidents registered in Dayyer, Bushehr province, Iran (2015)
}

\author{
Zahra Momeni ${ }^{1}$, Moslem Koohgardi ${ }^{2,},{ }^{*}$, Masoud Mohammadi $^{3}$ \\ 1- MSc in Epidemiology, Dayyer City Health Network, Bushehr University of Medical Sciences, Bushehr, Iran. \\ 2- MSc Student in Health Education \& Health Promotion, Rafsanjan University of Medical Sciences, Rafsanjan, Iran. \\ 3- MSc in Epidemiology, Department of Social Medicine, Faculty of Medicine, Kermanshah University of Medical \\ Sciences, Kermanshah, Iran.
}

\section{Article Info}

* Corresponding authors:

Moslem Koohgardi,

E-mail:

mkoohgardi @yahoo.com

\section{Article history}

Received: Oct, 2017

Accepted: Nov, 2017

Print ISSN: 2251-8096

Online ISSN: 2252-0902

DOI:

Peer review under responsibility of Journal of Occupational Health and Epidemiology

\section{Abstract}

Background: Awareness of the overall status of incidents and accidents and also the relevant causes can be extremely fruitful in preventing them. Therefore, this study aimed to investigate the epidemiology of incidents and accidents in Dayyer, Province of Bushehr, Iran.

Materials and Methods :This cross-sectional study was conducted on 838 incident cases obtained from the registered data from the accidents and incidents registry of Dayyer health care system in 2015. The data were collected using a checklist. Then, the data were analyzed using descriptive (prevalence and percentage) and inferential (chi-square test and t-test) statistics.

Results: Out of 838 registered incident cases, the overall rate of incidents was 15.1 in 1000 individuals; the rates among men and women were 22.6 and 7.3 in 1000, respectively. The highest rate belonged to men $(n=637$; $76.0 \%$ ) and the age range of $20-29$ years ( $n=201 ; 24.0 \%)$. The highest rate of accidents has been reported in urban regions ( $n=661 ; 78.9 \%$ ) which occurred at home ( $n=340 ; 40.6 \%)$ and in autumn $(n=236 ; 28.2 \%)$. The highest rate of incidents belonged to trauma (25.4\%), motorcycle crash (22.6\%), and snakebite and scorpion sting (13.4\%).

Conclusions: The highest occurrence rates of incidents and accidents were observed among men and the young compared to other groups in Dayyer. Thus, it is necessary that the appropriate programs be prepared for the public, particularly the young, via mass media regarding observing traffic codes and helping self-protection.

Keywords: Incidents, Accidents, Incidence, Epidemiology, Iran

\section{Introduction}

Any event which may lead to the suspension of important activities of the community or an organization or cause damages is called an incident. An accident is a sudden disaster, or serious or catastrophic event causing financial and personal injury, and its occurrence may have a natural or human aspect (1).

Accidents and injuries are the leading and avoidable causes of illnesses and deaths in most countries in the world. In addition, the

(c) The Author(s) 2018. Published by Rafsanjan University of Medical Sciences Press.

All rights reserved. For permissions, please e-mail: johe.rums@gmail.com, johe@rums.ac.ir

JOHE, Winter 2018; 7 (1) 
damages caused by accidents will be the second leading cause of disability in developing countries and the third cause of death and disability worldwide by 2020 (2). Injuries due to incidents account for $12 \%$ of the burden of diseases and the highest mortality rate due to unintentional accidents in the world (1, 3). Accidents, like illnesses, have their own natural trend and follow an epidemiologic pattern, i.e., the interaction of the agent, the host, and the environment; in addition, their incidence is higher in some age groups, at certain times of the day or week, and in certain places (4).

Traffic accidents, drowning, falling, burns, violence, or annual wars cause the death of more than 5 million people and injury in millions of people annually. These events account for $9 \%$ of deaths, are threats to the health of each country (5), and may occur at any age (6). Damage is a major risk to adult health and the most common cause of death in the ages of 1-4 years worldwide.

Iran has high levels of incident traffic accidents in worldwide (7). Therefore, incidents are of the most common health problems in Iran, in which, over one million and two hundred thousand disability adjusted life years (DALY) are lost due to these problems (8). Furthermore, according to published statistics, $3 \%$ of all referrals to health care centers have been due to injuries due to incidents and traffic accidents (9). In a study conducted in the city of Saqqez, Iran, the overall incidence of events in all men and women was reported to be 10.6 per thousand (10). In addition, in a study in Lordegan City, Iran, the incidence of events and accidents among men and women was 5.6 and 2.9 per thousand, respectively (11).

The present decade has been called the Decade of Action for Road Safety (12). According to published statistics, damage due to incidents is one of the five major causes of death in different age groups in advanced and developing countries $(13,14)$ and one of the most important causes of disabilities in developed countries worldwide. Moreover, the costs and expenses of incidents are exorbitant, in addition, disabilities caused by incidents result in the loss of active labor force along with millions of useful working hours (14).

Incidents are categorized in the group of non-communicable diseases, and their prevention requires individuals' increased awareness of safety principles. Therefore, awareness of the general status of incidents and their causes can be effective in preventing them and also in efficient care and treatment planning in order to reduce mortality due to incidents (7-10). Since such a study had hitherto not been carried out in Dayyer City, Iran, the present study was conducted to assess the epidemiology of accidents and incidents in this city.

\section{Material and Methods}

To carry out this cross-sectional study, permission was obtained from the healthcare network authorities to receive data of incidents and accidents. Then, data obtained from the records of incidents and accidents in Dayyer City from April to March 2015, were investigated.

Bandar Dayyer is one of the cities located in the south of Bushehr Province, Iran, 208 km from the center of the province. The city is enclosed from the north by the cities of Dashti and Tangestan, from the east by the cities of Jam and Bandar Gangan, and from the south and west by the Persian Gulf. Its climate is generally warm and humid. Winter in this city is similar to spring in the cold provinces of the country. According to the census in 2011, the population of the city was 52,523 , including 26,198 women and 26,395 men (15).

The study population comprised the total population (both city and village) covered by the health care network of the city of Dayyer, which consisted of 55,424 people, including 28,126 men and 27,298 women, of which, 44,020 resided in urban areas and 
11,404 in rural areas. A total number of 838 cases of incidents and accidents were recorded from April to March 2015. All cases recorded in terms of age groups, gender, type of incident, location of incident, area of incident, season of occurrence of the incident, and the outcome of the incident (the data of which were fully recorded) were extracted. The cases recorded with incomplete data (data lacking the age group, type of incident, gender, and other information requested by the study) were excluded. The data were then collected in a checklist.

Finally, the collected data were analyzed in SPSS software (version 16, SPSS Inc., Chicago, IL, USA). Results for quantitative and qualitative variables were reported as "mean \pm standard deviation" and "rate (percent)", respectively. Chi-square test and t-test were used to determine the relationship between qualitative variables and calculate the mean age of the injured, respectively. The significance level was considered to be 0.05 in all tests.

\section{Results}

Of the 838 recorded incidents, 637 cases $(76.0 \%)$ and 201 cases $(24.0 \%)$ were related to men and women, respectively. The total population covered by the health care network of Dayyer City was 55,424 individuals, of which 28126 (50.7\%) were men and 27298 (49.3\%) were women. Accordingly, the overall incidence of events in all men and women was 1.15 per 1000 people; 22.2 and 7.3 per 1000 among men and women, respectively.

The mean age of the injured was $27.10 \pm$ 15.75 years (with the age range of $1-81$ years); the mean age of men and women was, respectively, $27.05 \pm 14.92$ and 27.26 \pm 18.19 years. The results showed that the highest accident rates were related to trauma with 213 cases (25.4\%), motorcycle with 189 cases (22.6\%), and scorpion stings and snakebites with 112 cases (13.4\%), respectively (Figure 1 ).

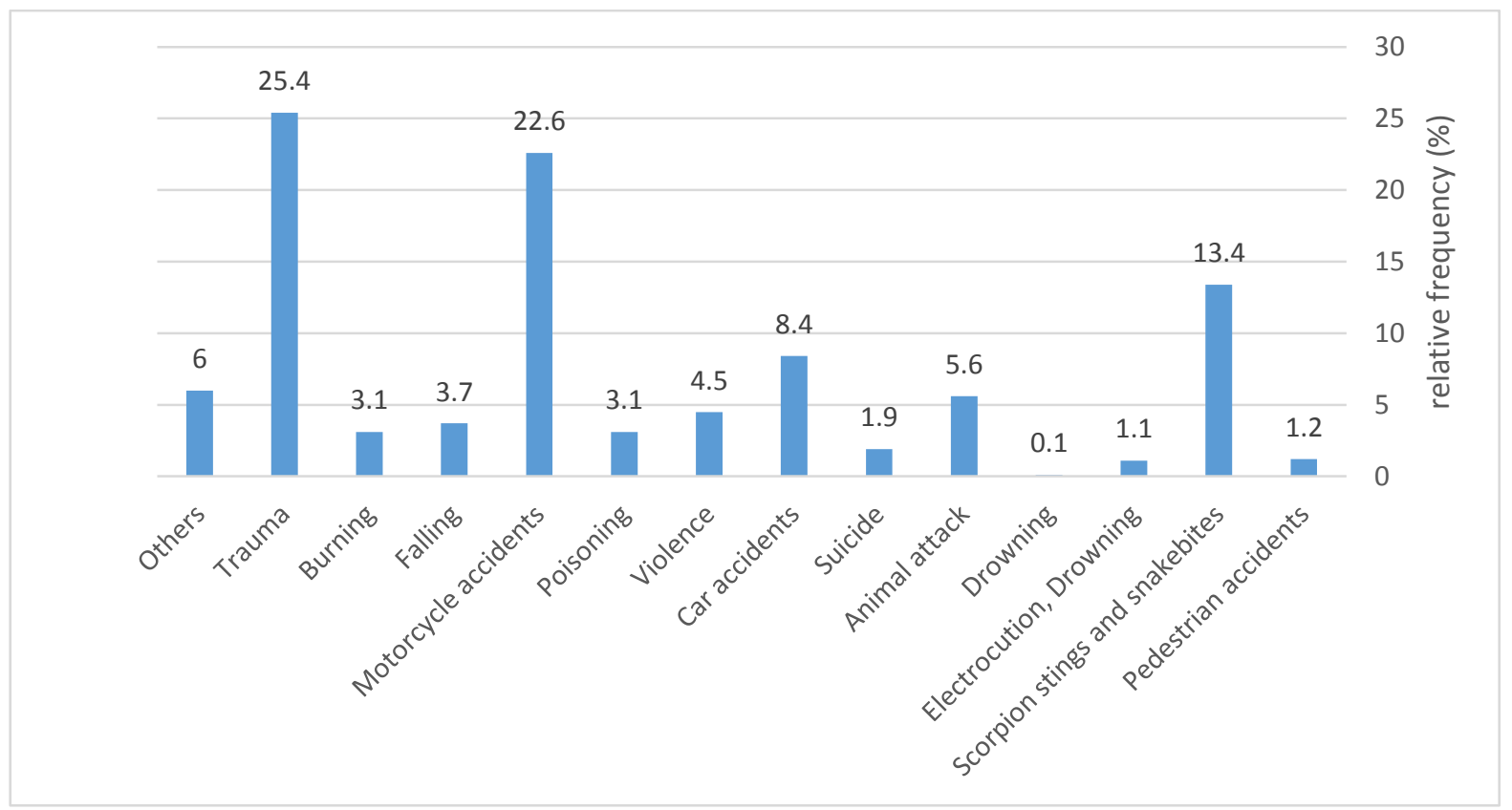

Figure 1: Frequency distribution of incidents and accidents in Dayyer City, Iran, in 2015

The distribution of accident victims according to age and sex groups showed that the highest incidence rates were in the age groups of 20-29 years with 295 cases
$(35.2 \%)$ and $10-19$ years with 162 cases (19.3\%). Furthermore, the lowest number of cases of incidents was observed in the age group of $70-79$ years with 20 cases $(2.4 \%)$ 
and over 80 years with 4 cases $(0.5 \%)$. In all age groups, more men were affected than women.

The investigation of age distribution in accidents showed that the rate of pedestrian accidents was higher in the age group of 19 years $(60 \%)$ and suicide in the age group of $10-19$ years (37.5\%). In addition, the incidents of scorpion sting and snakebite (34.8\%), electrocution (33.3\%), animal attack (38.3\%), car accident (38.7\%), violence $(55.3 \%)$, poisoning $(53.8 \%)$, motorcycle accident (32.8\%), falling
$(51.6 \%)$, burning $(30.8 \%)$, and trauma $(33.3 \%)$ were higher in the age group of 20 29 years compared to other age groups.

Table 1 shows the frequency distribution of the cause of incident in terms of gender. As can be seen in this table, except for the incidents of scorpion sting and snakebites and suicide, which were higher among women than men, incident rates were higher among men in other cases; this Difference was statistically significant $(\mathrm{P}<$ 0.001).

Table 1: Frequency distribution of the cause of incident in Dayyer City, Iran, in terms of gender in 2015

\begin{tabular}{cccc}
\hline \multirow{2}{*}{ Type of incident } & \multicolumn{2}{c}{ Gender } & Total \\
\cline { 2 - 4 } & $\begin{array}{c}\text { Women } \\
\text { Prevalence (\%) }\end{array}$ & $\begin{array}{c}\text { Men } \\
\text { Prevalence (\%) }\end{array}$ & P \\
\hline Pedestrian accident & $1(10)$ & $9(90)$ & 10 \\
\hline Scorpion sting and snakebite & $57(50.9)$ & $55(49.1)$ & 112 \\
\hline Electrocution & $1(11.1)$ & $8(88.9)$ & 9 \\
\hline Drowning & 0 & $1(100)$ & 1 \\
\hline Animal attack & $12(25.5)$ & $35(74.5)$ & 47 \\
\hline Suicide & $11(68.8)$ & $5(31.2)$ & 16 \\
\hline Car accident & $19(27.1)$ & $51(79.2)$ & 70 \\
\hline Violence & $2(5.3)$ & $36(94.7)$ & 38 \\
\hline Poisoning & $10(38.5)$ & $16(61.5)$ & 26 \\
\hline Motorcycle accident & $14(7.4)$ & $175(92.6)$ & 189 \\
\hline Falling & $7(22.6)$ & $24(77.4)$ & 31 \\
\hline Burning & $7(26.9)$ & $19(73.1)$ & 26 \\
\hline Trauma & $40(18.8)$ & $173(81.2)$ & 213 \\
\hline Other cases & $20(40)$ & $30(60)$ & 50 \\
\hline Total & $201(24)$ & $637(76)$ & 838
\end{tabular}

Table 2 shows the frequency distribution of the cause of incidents in terms of the season of the incident. According to this table, in general, the highest and the lowest rates of incidents occurred in the fall with 236 cases $(28.2 \%)$ and in the summer with 176 cases (21.0\%), respectively. This relationship was also statistically significant $(\mathrm{P}<0.001)$.

Table 3 shows the frequency distribution of the cause of incident in terms of the area of the incident. According to this table, the highest rates of events, respectively, occurred in urban areas with 661 cases (78.9\%) and in rural areas with 115 cases $(13.7 \%)$. In addition, the lowest rate of incidents occurred in the outskirts of the cities and villages with 62 cases (7.4\%). The most frequent incidents in the city were trauma and motorcycle accidents, and in the village were scorpion stings and snakebites and motorcycle accidents, respectively. As shown in table 3 , there is a significant relationship between the cause of the incident and the incident area $(P<0.001)$. 
Table 2: Frequency distribution of the cause of the incident in Dayyer City, Iran, in terms of season in 2015

\begin{tabular}{|c|c|c|c|c|c|c|}
\hline \multirow{2}{*}{ Type of incident } & \multicolumn{4}{|c|}{ Season } & \multirow{2}{*}{ Total } & \multirow{2}{*}{$\mathbf{P}$} \\
\hline & Spring & Summer & Fall & Winter & & \\
\hline Pedestrian accident & $6(60)$ & $1(10)$ & $2(20)$ & $1(10)$ & $10(100)$ & \multirow{15}{*}{$<0.001$} \\
\hline $\begin{array}{l}\text { Scorpion sting and } \\
\text { snakebite }\end{array}$ & $25(22.3)$ & $36(32.2)$ & $40(35.7)$ & $11(9.8)$ & $112(100)$ & \\
\hline Electrocution & $1(11.1)$ & $1(11.1)$ & $2(22.2)$ & $5(55.6)$ & $9(100)$ & \\
\hline Drowning & $1(100)$ & 0 & 0 & 0 & $1(100)$ & \\
\hline Animal attack & $8(17)$ & $12(25.5)$ & $15(32)$ & $12(25.5)$ & $47(100)$ & \\
\hline Suicide & $2(12.5)$ & 5 (31.2) & $2(12.5)$ & $7(43.8)$ & $16(100)$ & \\
\hline Car accident & $18(25.7)$ & $10(14.3)$ & $14(20)$ & $28(40)$ & $70(100)$ & \\
\hline Violence & $16(42.1)$ & $3(7.9)$ & $3(7.9)$ & $16(42.1)$ & $38(100)$ & \\
\hline Poisoning & $3(11.5)$ & $6(23.1)$ & $8(30.8)$ & $9(34.6)$ & $26(100)$ & \\
\hline Motorcycle accident & $39(20.6)$ & $42(22.2)$ & $42(22.2)$ & $66(35)$ & $189(100)$ & \\
\hline Falling & $9(29)$ & $6(19.4)$ & $10(32.2)$ & $6(19.4)$ & $31(100)$ & \\
\hline Burning & $9(34.6)$ & $7(27)$ & $3(11.5)$ & $7(26.9)$ & $26(100)$ & \\
\hline Trauma & $59(27.7)$ & $42(19.7)$ & $66(31)$ & $46(21.6)$ & $213(100)$ & \\
\hline Other cases & $6(12)$ & $5(10)$ & $29(58)$ & $10(20)$ & $50(100)$ & \\
\hline Total & $202(24.1)$ & $176(21)$ & $236(28.2)$ & $224(26.7)$ & $838(100)$ & \\
\hline
\end{tabular}

In terms of the location of incidents, 340 cases $(40.6 \%), 225$ cases (26.8\%), 129 cases $(15.4 \%)$, and 82 cases $(9.8 \%)$ occurred at home, in the street, at work, and on the highway, respectively. Moreover, incidents in public places, schools, and sports facilities accounted for less than $10 \%$ of the cases.
In terms of the outcome of the incident, 833 individuals $(99.4 \%)$ were treated and 5 $(0.6 \%)$ died. Out of 5 deaths, 2 cases $(0.2 \%)$ were due to suicide, $1(0.1 \%)$ due to drowning, 1 due to falling, and 1 due to car accidents. Moreover, 3 cases $(0.4 \%)$ and 2 cases $(0.2 \%)$ of deaths were among men and women, respectively.

Table 3: Frequency distribution of the cause of the incident in Dayyer City, Iran, in terms of incident area in 2015

\begin{tabular}{ccccc}
\hline \multirow{2}{*}{ Type of incident } & \multicolumn{3}{c}{ Type of incident } & Total \\
\cline { 2 - 5 } & City & Village & $\begin{array}{c}\text { Outside the city } \\
\text { and village }\end{array}$ & \\
\hline Pedestrian accident & $8(1.2)$ & $2(1.7)$ & 0 & $8(100)$ \\
\hline $\begin{array}{c}\text { Scorpion sting and } \\
\text { snakebite }\end{array}$ & $78(11.8)$ & $32(27.8)$ & $2(3.2)$ & $112(100)$ \\
\hline Electrocution & $8(1.2)$ & $1(0.9)$ & 0 & $9(100)$ \\
\hline Drowning & $1(0.2)$ & 0 & 0 & $1(100)$ \\
\hline Animal attack & $38(5.7)$ & $8(7)$ & $1(1.6)$ & $47(100)$ \\
\hline Suicide & $8(1.2)$ & $6(5.2)$ & $2(3.2)$ & $16(100)$ \\
\hline Car accident & $42(6.4)$ & $7(6.1)$ & $21(33.9)$ & $70(100)$ \\
\hline Violence & $30(4.5)$ & $2(1.7)$ & $6(9.7)$ & $38(100)$ \\
\hline Poisoning & $23(3.5)$ & $3(2.6)$ & 0 & $26(100)$ \\
\hline Motorcycle accident & $146(22.1)$ & $29(25.2)$ & $14(22.6)$ & $189(100)$ \\
\hline Falling & $17(2.6)$ & $7(6.1)$ & $7(11.3)$ & $31(100)$ \\
\hline Burning & $21(3.2)$ & $5(4.3)$ & 0 & $26(100)$ \\
\hline Trauma & $198(30)$ & $8(7)$ & $7(11.3)$ & $213(100)$ \\
\hline Other cases & $43(6.5)$ & $5(4.3)$ & $2(3.2)$ & $50(100)$ \\
\hline Total & $661(100)$ & $115(100)$ & $62(100)$ & $838(100)$ \\
\hline
\end{tabular}

\section{Discussion}

This cross-sectional study was conducted in Dayyer City in 2015 to evaluate the epidemiology of incidents and accidents. In this study, out of a total of 838 recorded incidents, 637 cases (76.0\%) and 201 cases
(24.0\%) of incidents were men and women, respectively. The overall incidence of events in all men and women was 15.1 per 1000 individuals, and separately, 22.6 and 7.3 per 1000 individuals among men and women, respectively. The results of this study are in 
agreement with the study of Mohammadi et al. (10) in terms of the finding that the incidence of events among men was higher than that among women. In their study, the overall incidence of accidents and incidents was 10.6 per 1000 individuals; 15.1 per 1000 among men and 5.9 per 1000 among women (10). In addition, the highest rates of incidents among men and women were 1830 cases $(72.5 \%)$ and 695 cases (27.5\%), respectively (10). Other studies, like the present study, indicate the higher incidence rate of events among men (11, 16). The higher rate of incidents among men can be due to occupational activity and the greater use of vehicles by men than women. Hence, more measures must be taken with intergovernmental partnerships and participation of local people and authorities in the field of providing and promoting the safety of occupations of men (17).

Distribution of the cause of incidents by gender showed that, except for the incidents of scorpion stings and snakebites and suicides that were higher among women than men, men were more likely to be exposed to incidents. This indicates the greater high-risk behavior and daring among men than women; however, the incidents of scorpion stings and snakebites were more likely to occur among women than men, which is not consistent with the study of Soudjani (11). Cases of scorpion stings and snakebites in the city of Dayyer were more frequent in the fall and at home [86 cases $(78.6 \%)]$. Therefore, it can be concluded that due to the geographical location, climate changes, and coastal position of this city, with increasing rainfall in the fall, snakes and scorpions come out of the soil and bushes and enter homes through open doors and windows. Since women are at home, they are more at risk than men. Furthermore, there were more suicide cases among women compared to men; this is consistent with the results of the study by Soudjani (11). This may be due to the more sensitive temperament and greater vulnerability of women than men, or their higher levels of mood, emotional, and anxiety disorders, and less social support in protecting women's rights relative to men. In this study, the mean age of the injured was $27.10 \pm 15.75$ years; it was $24.00 \pm$ 12.80 years in the study by Rafiei in the city of Aq Qala, Golestan Province, Iran (17). In this study, the majority of the injured were, respectively, youth and adolescents. In addition, most of the incidents occurred in the third decade of life of individuals, which was similar to the studies by Fazel in Kashan, Iran, (18) and Rafiei in Aq Ghala, Golestan (17). In these studies, most of the injured were in the age group of 20-29 years, indicating their greater energy and joy, negligence and carelessness which have led to an increase in incidents in this age group.

The results of this study showed that most of the pedestrian accidents occurred in the age group of 1-9 years. This issue could be directly related to distraction and inadequate supervision by adults. Therefore, parents should be provided the necessary training to be more cautious regarding children when crossing the roads. Suicide was more frequent in the age group of 10-19 years, which is similar to the study by Rafiei in Golestan (17); this issue also requires training of life skills related to this vulnerable group in schools.

The incidents of scorpion stings and snakebites, electrocution, animal attack, car accident, violence, poisoning, motorcycle accident, falling, burning, and trauma were higher in the age group of 20-29 years than other age groups. Mohammadi et al. investigated the frequency of accidents and incidents in the city of Saqqez, Iran, in the age groups of 15-25 and 26-35 years (10). They found that the highest incidence rates were related to suicide and car accident among women, and car accidents and violence among men. Souri et al. conducted a study with the purpose of identifying the 
epidemiological pattern of non-lethal incidents in Iran (20). They reported that the highest rate of incidents in the age groups of 15-25 and 26-35 years were due to traffic accidents and suicide among men and women, respectively. In the epidemiological investigation of driving accidents in Isfahan, Iran, by Fanian et al. (21), the highest rates of traffic accidents and deaths were reported in the age group of 16-25 years. The greater incidence of events in this age group, given that these individuals are at working age, can indicate the young person's strength and, consequently, the inexperience of this age group in dealing with everyday problems, non-compliance with laws and regulations, and their vulnerability. Since this age group is economically considered as an active group of the community, the greater attention of health policy makers is required to adopt security measures in this respect.

In this study, the highest rates of incidents were related to trauma and motorcycle accident with 213 cases (25.4\%) and 189 cases $(22.6 \%)$, respectively. In general, the highest and lowest rates of incidents, respectively, occurred in the fall with 236 cases $(28.2 \%)$ and summer with 176 cases (21.0\%). However, in the study by Rafiei in Golestan, most of the events occurred in the spring, and then, in the summer (17). In a study by Rostami in Ardebil, Iran, the highest rate of incidents was related to the summer (22), in addition, in a study by Mobasheri in Fasa, Iran, the highest rate of incidents among children was observed in the winter (23). In this port city, due to changes in the climate from summer to fall, and due to the reopening of schools, vehicle traffic increases, resulting in an increase in incidents in this season.

In terms of the region of incident, the highest number of incidents occurred in urban areas, and then, in rural areas, and the lowest rate of incidents occurred in the outskirts of the city and villages, respectively. Moreover, in terms of the location of incident, the highest rates of incidents were related to the home and streets, respectively. Similar to the present study, Rodriguez (13), Khosravi (17), Rafiei (24), Kalantari (25), and Mohammadi (26) also reported the highest rate of incidents in the city. In addition, in the studies by Kalantari (17) and Rafiei (24), the highest rate of incidents occurred on the street, and then, at home. Furthermore, in the study by Gholamaliyi, the most frequent place of occurrence of traffic accidents was the street (27). The results of these studies are not consistent with the present study in terms of the location of incidents. This difference in the results of the present study with other studies may be due to weakness in the data recording system of incidents in terms of the location of the incident in Dayyer, because, due to the high rate of incidents among men and their occupations which are usually outdoors, most of the incidents are expected to occur outside the home.

In terms of the outcome of the incidents, most of the individuals were treated and only $0.6 \%$ of the cases resulted on death, indicating low mortality rate due to incidents in this city, which is consistent with the study by Olawale (28).

In this study, the highest rates of incidents in the city were, respectively, related to trauma and motorcycle accident. In addition, in the village, this rate was, respectively, related to scorpion stings and snakebites and motorcycle accident. In a study by Neghab et al., which was conducted to investigate accidents and incidents in the city of Shiraz, Iran, it was found that burnings and damages caused by sharp objects were more prevalent among women both in urban and rural areas (29). However, poisoning and falling from a height have occurred more among men. As the items examined and the location chosen for the study differed from the rest of the researches by colleagues, the statistics were slightly different. In the present study, 
the increase in the rate of trauma in the city could be due to the advancement of technology, the increase in the number and speed of vehicles, and the change in the way of driving. Moreover, the increased rate of motorcycle accidents in the cities and villages indicate the unbridled use of motorcycles in the city of Dayyer and a lack of attention of individuals to traffic regulations. Therefore, training all residents in the cities and villages on traffic regulations and attention to the principles of safety and protection of buildings to prevent entry of animals, especially scorpions and snakes, to buildings, especially among villagers, seem necessary. The need to train individuals to reduce incidents has also been well reported in the study by Mohammadi (26) and the target group of men of 18 to 35 years of age, with the highest incidence of injuries, has been introduced as an incident prevention target group. Such an explanation in the policy of preventing accidents can be considered by the policy makers of the Ministry of Health, Treatment, and Medical Education. In addition, it can be introduced as the first line of prevention of accidents and increasing of health awareness through health education in the health centers of the country.

The most prominent limitation of this study was the use of data from 2015 which were made available to authors; thus, the information was outdated. However, considering that the purpose of this study was to highlight the importance of incidents and accidents among mortality factors in the country and cities, and the need for more effective prevention and the use of such information in effective policies on prevention of incidents in the country; therefore, the authors were encouraged to use this information.

Considering the breakdown of incidents in this study in terms of age and gender groups, it is recommended that future studies on the issue of incidents and accidents in the city of Dayyer be carried out on the relationships and factors affecting the incidents to adopt appropriate policies in the field of prevention of accidents and incidents in this city.

\section{Conclusion}

The rate of occurrence of incidents in the city of Dayyer was higher among men and in the youth age group compared to other age groups. In addition, their most common causes were trauma, motorcycle accidents, and scorpion sting and snakebites. Therefore, the increased awareness of individuals is necessary to reduce incidents and possible complications caused by them. Therefore, prevention of incidents and accidents requires the training of all residents in the cities and villages, especially the youth, through public media to comply with driving guidelines and the use of personal protective equipment.

\section{Acknowledgments}

The authors of this article wish to thank the officials of the health and treatment network of the city of Dayyer, especially the chief of the center of accidents and incidents, for their cooperation regarding data collection.

Conflict of interest: None declared.

\section{References}

1. Kalantari Khalilabad $\mathrm{H}$, Pourahmad A, Yamani M, Rahnamaei M. Terminology of transportation and sandstorm management. Scientific-Research Quarterly of Geographical Data (Sepehr) 2008; 17(68):57-61.

2. Murray CJ, Lopez AD. Alternative projections of mortality and disability by cause 19902020: Global Burden of Disease Study. Lancet 1997; 349(9064):1498-504.

3. Sim TP, $\mathrm{Ng} \mathrm{KC.} \mathrm{Childhood} \mathrm{injuries:}$ prevention is always better than cure. Singapore Med J 2005; 46(3):103-5.

4. Ahmadpour A, Bigdeli R, Qochi Z, Karbord $A A$, ahmadi $S$. The study of the trend and outbreak of accident and incidents in Qazvin city in 2010. Edrak 2010; 5(19):38-42. 
5. World Health Organization. Health topics: Inguries. Geneve: Word Health Organization; 2014. Available from: http://www.who.int/topics/injuries/about/en/

6. Mohammadi $M$, Mohammadzadeh $M$, Ahmadi A, Esmaeili A. The trend of epidemiological investigation of accidents and injuries categorical data in the city of Saqez in 2014. Journal of Safety Promotion Injury Prevention 2017; 5(1):43-50.

7. Peden M, Scurfield R, Sleet D, Mohan D, Hyder AA, Jarawan E, et al. World report on road traffic injury prevention. Geneva: World Health Organization; 2004. 217 p.

8. Naghavi M, Abolhassani F, Pourmalek F, Lakeh M, Jafari N, Vaseghi S, et al. The burden of disease and injury in Iran 2003. Popul Health Metr 2009; 7:9.

9. Abbasi M, Sadeghi M, Azami AA, Esmaeili SM, Kavousi J, Aryafard A. Factors related to road traffic accidents leading to injury or death in Shahroud city. Journal of Safety Promotion Injury Prevention 2016; 4(2):8390.

10. Mohammadi M, Ahmadi A, Esmaeili A. The frequency of accidents in Saqez in 2014: a short report. Journal of Rafsanjan University of Medical Sciences 2017; 15(9):885-92.

11. Soodejani $M$, Shirani Faradonbeh $R$, Hashemi SA, Zahedi A, Dehghani A. Epidemiology of accidents and injuries in the city of Lordegan in 2012: a short report. Rafsanjan University of Medical Sciences 2015; 13(9):917-22.

12. Moront ML, Eiclielberger MR, Williams JA, Wiknson JD. The injured child: an approach to care. Pediatric Clinical North American 1994; 41(6):1201-26.

13. Khosravi Sh, Ghafari M. Epidemiological study of domestic accidents in urban and rural area of Shahrekord in 1999. Journal of Shahrekord University of Medical Sciences 2003; 5(2):54-64.

14. Mahram M, Derakhshandeh J, Jamshidi MR, Yektaparast M. Study ofemergency \& domestic accidents cases in the patients which refered to the centers of health services in the province of zanjan in 1999. Journal of Zanjan University of Medical Sciences and Health Services 2001; 8(33):41-6.

15. Mehrabian A, Naqinezhad A, Mahiny AS, Mostafavi $\mathrm{H}$, Liaghati $\mathrm{H}$, Kouchekzadeh $\mathrm{M}$. Vegetation mapping of the Mond Protected Area of Bushehr Province (south-west Iran). J Integr Plant Biol 2009; 51(3):251-60.
16. Kalaiselvana G, Dongre AR, Mahalakshmy T. Epidemiology of injury in rural Pondicherry, India. J Inj Violence Res 2011; 3(2):62-7.

17. Rafiei N, Latifi M, Sensebli Gh, Mohammadi A. Epidemiology of injury in Aq-Qala cityIran, 2007-2012. Journal of Safety Promotion and Injury Prevention 2014; 2(4):273-80.

18. Fazel MR, Fakhrarian $\mathrm{E}$, Tabesh $\mathrm{H}$, Aghadoost D, Azordegan F. Epidemiological study on injuries in Kashan form 2004 to 2006. Feyz 2008; 11(5):28-31.

19. Charkazi A, Esmaeili A, Garkaz G, Qoreishi Z, Gerey S, Nazari S. Epidemiologic survey of road traffic accidents in patients admitted in emergency department of Alejalil hospital in Aq-Qala city, Golestan province. Journal of Health 2012; 3(2):42-9.

20. Soori H, Akbari M, Eini E, Zali AR, Naghavi M, Kordi Borujeni E. Epidemiology of nonfatal accidents in Iran. Advances in Nursing and Midwifery 2008; 18(60):45-50.

21. Fanian H, Ghadipasha M, Goddousi A, Abedi $\mathrm{MH}$, Farajzadegan Z, Kazemi Robati A. Epidemiologic evaluation of traffic accidents in Isfahan, (2002-2003). Forensic Medicine 2007; 13(2):87-91.

22. Rustami Kh, Zohouri H, Sayad Rezaii E. The epidemiology study of mortality death related car accidents. Journal of Ardabil University of Medical Sciences 2008; 8(4):381-6.

23. Mobasheri F, Azizi $H$, Rastbaf F. The epidemiological pattern of injuries among children under 15 years of age in Fasa in 2013. Journal of Fasa University of Medical Sciences 2016; 6(1):69-78.

24. Kalantari S, Mehravar F, Kord F, Ghana S, Aghapour SA, Mohammadi R, et al. The epidemiology of trauma in Golestan province, Northeast Iran. J Community Health Res 2017; 6(2):102-8.

25. Gholamaliee B, Khazaei S, Jamorpour S, Mohammadian Hafshejani A, Salehinia $H$. Epidemiological assessing of motorcyclists' countrylevel traffic accidents, 2013. Pajouhan Scientific Journal 2015; 14(1):1221.

26. Olawale OA, Owoaje ET. Incidence and pattern of injuries among residents of a rural area in South-Western Nigeria: a communitybased study. BMC Public Health 2007; 7:246.

27. Neghab M, Habibi M, Rajaifard AAR, Choobineh AR. Home accidents in Shiraz during a 3-year period (2000-2002). Journal of Kermanshah University of Medical Sciences 2008; 11(4):428-40. 